\title{
Impact of Neonatal Thyroid Hormone Insufficiency and Medical Morbidity on Infant Neurodevelopment and Attention Following Preterm Birth
}

\author{
Nevena Simic, M.A., ${ }^{1,2}$ Elizabeth V. Asztalos, M.D., FRCPC, ${ }^{3,4}$ and Joanne Rovet, Ph.D. ${ }^{1,2,4}$
}

Background: Infants born preterm are at risk of both transiently reduced thyroid hormone levels and impaired neurocognitive development, including attention deficits. The objective of this study was to examine the effects of reduced thyroid hormone levels on general neurodevelopment and attention at 3 months corrected age.

Methods: Sixty-four infants born 24 to 35 weeks gestation were stratified into four gestational age groups: Group A, 23-26 weeks $(n=10)$; Group B, 27-29 weeks $(n=23)$; Group C, 30-32 weeks $(n=20)$; Group D, $33-35$ weeks $(n=11)$. Controls were 33 healthy infants born full-term (Group E). In preterm only, free thyroxine $\left(\mathrm{FT}_{4}\right)$, triiodothyronine $\left(\mathrm{T}_{3}\right)$, and thyrotropin $(\mathrm{TSH})$ were measured at 2 and 4 weeks of life and at 40 weeks postconceptional age. At 3 months corrected age, all infants were assessed with the Bayley Scales of Infant Development-Second Edition (BSID-II), from which both mental development index (MDI) and psychomotor development index (PDI) scores and four indices of attention were derived: sustained attention, selective attention, attention shift, and total attention.

Results: Gestational age-stratified preterm groups differed significantly in $\mathrm{T}_{3}$ and $\mathrm{FT}_{4}$ levels at 2 and 4 weeks of life in infants born less than 27 weeks gestation. Preterm infants overall scored significantly below full-term on BSID-II MDI and PDI, selective, sustained, and total attention scales. In the preterm group, $\mathrm{FT}_{4}$ levels were positively associated with PDI and selective, sustained, and total attention.

Conclusions: Reduced levels of thyroid hormone in the neonatal period in preterm infants are associated with a reduced neurocognitive outcome in the attention domain at 3 months corrected age.

\section{Introduction}

$\mathbf{T}$ HYROID HORMONE (TH) Is a critical endocrine regulator of fetal brain development (1). Although $\mathrm{TH}$ is required throughout gestation, the fetal thyroid does not produce its own TH in appreciable amounts until the third trimester (2). Given that TH receptors are evident in fetal brain tissue by the 10th week of gestation (3) and maternal thyroxine $\left(\mathrm{T}_{4}\right)$ crosses the placental barrier by the second month of pregnancy $(4,5)$, maternal $\mathrm{TH}$ is thought to play a major functional role in fetal brain development until the fetal thyroid comes fully online at birth. In preterm infants, however, the third-trimester maternal supply of $\mathrm{TH}$ is cut short, leading in most infants to a transient period of hypothyroxinemia during what should have been the latter part of pregnancy (6). This transient hypothyroxinemia, which lasts longer and is more severe in infants of lower gestational age (7), can adversely affect subsequent neurodevelopment (8-10).
Among preterm infants, a variety of neurodevelopmental deficits are commonly seen, particularly if infants have extremely low birth weights $(<1000 \mathrm{~g})$, respiratory problems, or any form of neurological injury (11-13). Inattention is one of the most commonly reported deficits in preterm children (14). A previous study on infants with intrauterine or neonatal $\mathrm{TH}$ deficiency, including a small sample of infants born preterm, showed an association between decreased fetal or maternal TH supply and poor attention at 6 months of age (15). However, because this study involved only a small preterm sample and did not cover the full spectrum of preterm gestational ages, and it did not assess different specific subdomains of attention (such as the abilities to sustain, select, or shift attention), its findings are limited. Furthermore, since the medical complications and illnesses experienced by preterm infants can lead to alterations in levels of TH (16), this too may contribute to the detrimental effect of transient hypothyroxinemia of prematurity. The objective of this study is to determine if

\footnotetext{
${ }^{1}$ Department of Psychology, University of Toronto, Toronto, Ontario, Canada.

${ }^{2}$ Neurosciences and Mental Health Research Program, Hospital for Sick Children, Toronto, Ontario, Canada.

${ }^{3}$ Department of Newborn \& Developmental Paediatrics, Sunnybrook Health Sciences Centre, Toronto, Ontario, Canada.

${ }^{4}$ Department of Pediatrics, University of Toronto, Toronto, Ontario, Canada.
} 
there is any relationship between TH levels and neurodevelopmental findings, especially those related to attention, and whether neonatal illness is also a contributing factor.

The present article describes our findings at 3 months corrected age from a cohort of preterm and full term infants, all of whom were prospectively studied at 3, 6, and 14 months of age. In the preterm group, we determined $\mathrm{TH}$ levels and documented neonatal morbidity. Our primary hypothesis was that in comparison with full-term infants, the preterm group would show delayed neurodevelopment reflecting lower scores on both index scales of the Bayley Scales of Infant Development-Second Edition (BSID-II) and also specific attention factors. A secondary hypothesis was that higher neurodevelopmental index and attention scores would be positively correlated with higher $\mathrm{TH}$ levels and decreased neonatal medical morbidities.

\section{Materials and Methods}

Between November 2004 and May 2006, 67 preterm infants (23-35 weeks gestation) and 38 full-term ( $>37$ weeks) infants were recruited from the Neonatal Intensive Care Unit and postpartum care unit at the Sunnybrook Health Sciences Centre (SHSC) in Toronto, Canada, a University of Torontoaffiliated hospital. All infants, regardless of gestational age, were screened by day 3 of life for congenital hypothyroidism through the provincial screening program.

Preterm infants were stratified into four gestational age groupings: Group A, 23-26 weeks $(n=10)$; Group B, 27-29 weeks $(n=23)$; Group C, 30-32 weeks $(n=22)$; and Group D, 33-35 weeks $(n=12)$. Exclusion criteria were a positive newborn screen for congenital hypothyroidism or phenylketonuria, or a known or suspected congenital or chromosomal abnormality (e.g., Down syndrome).

Full-term infants with no neonatal morbidity and a negative newborn screen for congenital hypothyroidism were included in the control group (Group E, $n=33$ ). Additional exclusion criteria were child or maternal history of thyroid disease; maternal exposure to organic solvents, alcohol, and other substances of abuse; and maternal history of anticonvulsant or antirhythmic medication during pregnancy.

The study was approved by the Research Ethics Board at the two institutions involved in the study, SHSC and the Hospital for Sick Children (HSC). Parents or guardians of all participants provided signed informed consent.

\section{Study design}

This was a longitudinal prospective cohort study.

\section{Measures}

Demographic characteristics and medical morbidity. The following demographic information was obtained on all infants: gestational age, birth weight, sex, socioeconomic status (SES), level of maternal education, and Apgars at 1 and 5 minutes. SES was calculated using the Hollingshead index (17) based on a parent-completed baseline questionnaire.

The following medical morbidities were recorded for each preterm neonate: prenatal corticosteroids, highest level of bilirubin, sepsis, retinopathy of prematurity (ROP), patent ductus arteriosus (PDA), respiratory distress syndrome, bronchopulmonary dysplasia, cranial ultrasound-confirmed evidence of brain injury, and necrotizing enterocolitis. Infection was confirmed by the presence of a positive blood or cerebral spinal fluid culture. Infants born $<32$ weeks gestation and $<1250 \mathrm{~g}$ at birth were all screened for ROP and classified according to the international classification of ROP (18). Infants $<1500 \mathrm{~g}$ at birth all underwent at least one cranial ultrasound during their neonatal stay to determine the presence of any cranial abnormalities. Cranial ultrasound-confirmed brain injury included evidence of severe white matter damage (periventricular leukomalacia, late ventriculomegaly, peri- or intraparenchymal hemorrhage). Each morbidity was categorized as "present" or "absent" with the exception of ROP and hyperbilirubinemia, for which highest stage/zone or highest bilirubin point and age at peak were recorded respectively.

TH parameters. For preterm infants, blood samples were obtained at 2 and 4 weeks of age and 40 weeks postconceptional age (PCA). Blood samples were assayed centrally at HSC for free thyroxine $\left(\mathrm{FT}_{4}\right)$, total triiodothyronine $\left(\mathrm{T}_{3}\right)$, and thyrotropin (TSH) using the Bayer Immuno 1 or Bayer IMS analyzer (Siemens Healthcare Diagnostics, Deerfield, IL).

Neurodevelopmental outcome. At 3 months corrected age, neurocognitive ability was evaluated using the BSID-II (19), which is a validated, standardized, and widely used instrument which assesses mental and motor functioning in children aged 2 to 42 months. The 3-month age was chosen because this is an optimal early age for assessing attention with the BSID-II. The 3-month assessment was carried out by a clinically trained psychometrist with extensive formal clinical training and years of BSID-II testing experience. The BSID-II provides two main scales: the mental development index (MDI) and the psychomotor development index (PDI). The 3-month BSID-II item set also includes 10 items assessing different aspects of visual attention; these items were grouped into three distinct factors according to methods described elsewhere (9). The three factors and their constituent items are 1) selective attention (\#20 reacts to disappearance of face, \#24 head follow ring, \#27 discriminates novel visual pattern, \#29 prefers novelty, \#36 eyes follow rod); 2) sustained attention (\#25 regards cube for 3 seconds, \#26 habituates to visual stimulus, and \#28 displays visual preference); and 3) attention shift (\#23 glances from bell to rattle and \#32 eyes follow rolling ball). A total attention score was recorded from the sum of all 10 items.

The BSID-II behavior rating index (BRI), was completed after conducting the BSID-II assessment to provide testerrated measures of infant's attention and motor quality.

\section{Data management and analysis plan}

For several children, TH assessments were incomplete due to lab error, subject noncompliance, or tainted samples. In order to correct for this and improve power, we stratified subjects according to gestational age at birth and replaced missing values with the mean of \pm 2 nearest scores, as per the SPSS statistical analysis program (SPSS Inc., Chicago, IL). If the neurodevelopmental assessment was incomplete or not given to a particular child on whom we had a full set of thyroid measurements ( $n=7$ preterm infants), missing BSID-II 
scores were replaced with the mean of the corresponding gestational age group as per imputation methods described elsewhere (20).

Chi-square analyses were used to evaluate group differences in the binary (present/absent) medical morbidities. Multivariate analysis of variance (MANOVA) was used to test for group differences in demographics and nonbinary medical morbidities, TH levels, and 3-month BSID-II scores. Any demographic variable that significantly differed between groups was then used as a covariate in the analysis of thyroid and BSID-II results. Repeated measures ANOVA was used to compare the preterm group's TH levels at the different time periods. Post hoc analyses employed Tukey's honestly significant difference (HSD) test.

The final step in the analysis involved assessing the relative contribution of demographics (gestational age, birth weight, sex, SES), neonatal medical morbidity, and TH levels to neurodevelopment in the preterm population. To this end, we correlated each BSID-II variable differing significantly between preterm and control groups with each of the predictor variables. Indices showing significant associations singly were then entered together into a linear regression to determine their relative impact on neurodevelopment. A two-tailed significance level of 0.05 was applied to all analyses.

\section{Results}

Of the 67 original preterm infants, two in Group C were subsequently diagnosed with congenital hypothyroidism and one in Group D was deceased, thus reducing the sample size of Group C to 20 and Group D to 11. Additionally two infants from Group A, one from Group B, three from Group C, and one from Group D dropped out before the 3-month assessment.

\section{Demographic characteristics and medical morbidity}

Table 1 summarizes participant demographics according to gestational age groupings. Groups differed significantly $(p<0.01)$ in gestational age, birth weight, SES, and sex composition but not level of maternal education or mean

Table 1. Demographic and Morbidity Characteristics of the Sample

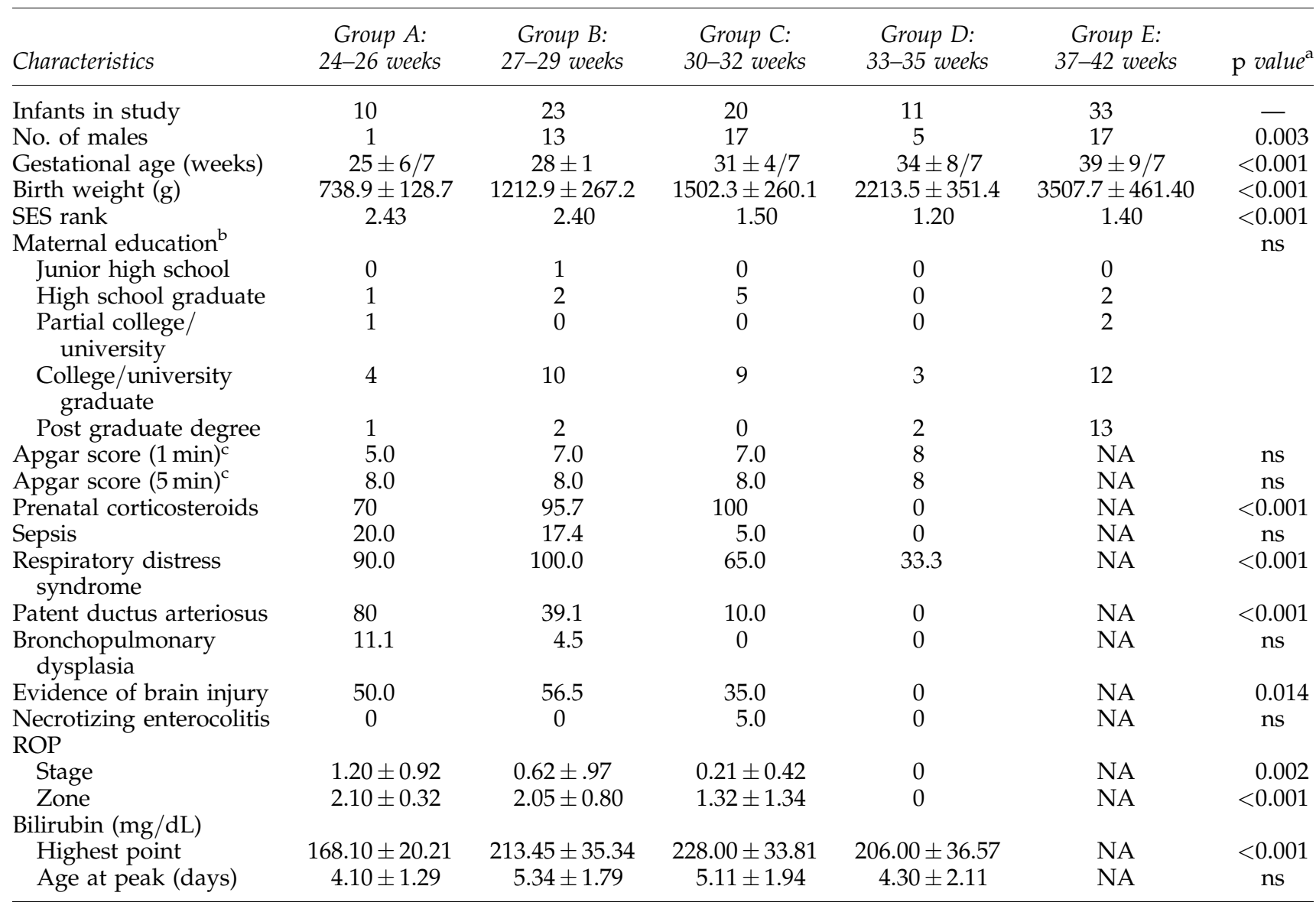

Data are expressed as mean $\pm \mathrm{SD}$ (gestational age, birth weight, ROP, and bilirubin), as the number of infants per level of maternal education, and as percentage of the group demonstrating presence of each medical morbidity.

${ }^{\mathrm{a}} p$ values reflect either MANOVA analyses (gestational age, birth weight, APGAR scores, SES) or chi-square analyses (sex, maternal education, medical morbidity).

${ }^{\mathrm{b}}$ Maternal education data was available for only 70 of the total 97 participants.

${ }^{\mathrm{C}}$ Data are expressed as medians.

SES, socioeconomic status; ROP, retinopathy of prematurity; ns, not significant; NA, not available. 
APGAR scores at 1 or 5 minutes. Therefore, sex and SES were used as covariates in evaluating for group differences in neurodevelopmental outcome, whereas birth weight, which is expected to covary with gestational age given that earlierborn infants are generally smaller, was not.

Table 1 also summarizes the medical morbidity findings for the different gestational age groups. Significant group differences were seen for use of prenatal corticosteroids $(p<0.001)$; presence of respiratory distress syndrome $(p<0.001)$, PDA $(p<0.001)$, and any evidence of brain injury $(p<0.05)$; highest point of bilirubin $(p<0.001)$; and ROP stage $(p=0.002)$ and zone $(p<0.001)$ reflecting the higher morbidity in lower gestational age groups. There were no differences in frequency of sepsis, bronchopulmonary dysplasia, necrotizing enterocolitis, or bilirubin age at peak.

\section{TH levels}

Table 2 summarizes the TH levels at 2 and 4 weeks of life and at 40 weeks PCA for the four preterm groups. For TSH, results revealed that although groups did not differ individually and there were no significant overall changes, the group by time interaction was significant $(p=0.011)$, reflecting the greater decline in TSH with postnatal age for infants born before 32 weeks.

For $\mathrm{FT}_{4}$, significant group differences were seen at all three time points $(p<0.05)$. Post hoc tests indicated 2-week $\mathrm{FT}_{4}$ levels were significantly lower in Group A compared to all other preterm groups $(p<0.01)$ and in Group B compared to Group D $(p<0.05) ; 4$-week $\mathrm{FT}_{4}$ levels were only significantly lower in Group A compared to all other preterm groups $(p<0.05)$; and at 40 weeks PCA, Groups A, B, and C all had significantly lower $\mathrm{FT}_{4}$ levels than Group D $(p<0.05)$. Repeated measures ANOVA revealed significant effects of time $(p=0.12)$ and significant group by time interactions $(p<0.001)$, indicating that in all preterm infants, $\mathrm{FT}_{4}$ levels increased with time since birth, especially among those with lower gestation.

Significant group differences were seen in $\mathrm{T}_{3}$ levels at 2 and 4 weeks $(p<0.001)$, but not 40 weeks PCA. Post hoc tests indicated 2-week $\mathrm{T}_{3}$ levels were significantly lower in Group A than in all other preterm groups $(p<0.05)$ and in Groups B and $C$ than Group D $(p<0.001)$, and 4-week $T_{3}$ levels were significantly lower in Groups A, B, and C versus Group D $(p<0.001)$. Repeated measures ANOVA revealed significant effects of time $(p<0.001)$ and group by time interaction $(p<0.001)$, reflecting the increase in $\mathrm{T}_{3}$ with time since birth among all preterm infants, especially those born with lower gestation.

\section{Neurodevelopmental results}

Table 3 summarizes the 3-month neurodevelopmental results. Significant group differences were observed on MDI $(p<0.05)$ with a trend for PDI $(p=0.052)$. Post hoc analyses revealed MDI differences were driven by Group B's lower scores than controls $(p<0.05)$. Controlling for sex or SES did not affect MDI group differences $(p=0.023$ and 0.036$)$, whereas PDI lost significance ( $p=0.096$ for both).

On the attention scales, significant group differences were observed for selective, sustained, and total attention, but not attention shift. Post hoc analyses revealed that Group A scored significantly below Group B and controls on selective attention, and below Groups B, C, and controls on sustained and total attention. Controlling for sex and SES did not alter the significant group differences on sustained, selective, or total attention indices.

There were no group differences on examiner-completed BRI attention and motor scales.

\section{$\mathrm{TH}$, illness, and neurodevelopmental outcome in preterm infants}

The proportional contribution of demographic factors, medical morbidities, and TH levels was considered only for scales on which preterm infants performed more poorly than full-term controls. Results are summarized in Table 4.

Regarding the two main BSID-II index scales, presence of a PDA and sepsis infection explained a significant portion of variance $(13.5 \%)$ in MDI. On attention indices, selective attention was significantly explained by high 2-week $\mathrm{FT}_{4}$, low 40-week PCA $\mathrm{T}_{3}$, and high bilirubin levels, which accounted for $19.2 \%$ of its variance; sustained attention was significantly explained by high 2-week $\mathrm{FT}_{4}$, use of prenatal corticosteroids, high bilirubin, and absence of PDA and sepsis, which accounted for $44.2 \%$ of its variance; total attention was sig-

Table 2. Thyroid Hormone Levels According to Gestational Age Group

\begin{tabular}{|c|c|c|c|c|c|c|c|}
\hline Thyroid hormone & $\begin{array}{c}\text { A: } 24-26 \text { weeks } \\
(\mathrm{n}=10)\end{array}$ & $\begin{array}{c}\text { B: } 27-29 \text { weeks } \\
(\mathrm{n}=20)\end{array}$ & $\begin{array}{c}C: \begin{array}{c}30-32 \text { weeks } \\
(\mathrm{n}=23)\end{array}\end{array}$ & $\begin{array}{c}D: 33-35 \text { weeks } \\
(\mathrm{n}=11)\end{array}$ & $\mathrm{p}$ value & $\begin{array}{l}\text { Observed } \\
\text { power }\end{array}$ & Post hoc comparisons \\
\hline \multicolumn{8}{|l|}{ TSH (mIU/L) } \\
\hline 2 weeks & $6.15 \pm 5.54$ & $5.02 \pm 2.97$ & $5.38 \pm 2.78$ & $3.66 \pm 2.12$ & ns & 0.277 & - \\
\hline 4 weeks & $4.05 \pm 4.83$ & $3.94 \pm 2.07$ & $3.49 \pm 1.40$ & $5.08 \pm 3.08$ & ns & 0.220 & - \\
\hline 40 weeks PCA & $5.83 \pm 5.62$ & $3.91 \pm 1.81$ & $3.32 \pm 0.62$ & $5.08 \pm 3.08$ & 0.088 & 0.548 & - \\
\hline \multicolumn{8}{|l|}{$\mathrm{FT}_{4}(\mathrm{pmol} / \mathrm{L})$} \\
\hline 2 weeks & $13.21 \pm 5.13$ & $18.58 \pm 3.95$ & $19.44 \pm 3.09$ & $22.45 \pm 2.51$ & $<0.001$ & 0.999 & $\mathrm{~A}<\mathrm{B}, \mathrm{C}, \mathrm{D} ; \mathrm{B}, \mathrm{C}<\mathrm{D}$ \\
\hline 4 weeks & $16.58 \pm 4.62$ & $20.17 \pm 3.53$ & $22.10 \pm 2.20$ & $20.98 \pm 2.14$ & $<0.001$ & 0.971 & $\mathrm{~A}<\mathrm{B}, \mathrm{C}, \mathrm{D}$ \\
\hline 40 weeks PCA & $18.59 \pm 2.09$ & $19.00 \pm 2.58$ & $18.79 \pm 1.13$ & $20.98 \pm 2.14$ & 0.024 & 0.734 & $\mathrm{~A}, \mathrm{~B}, \mathrm{C}<\mathrm{D}$ \\
\hline \multicolumn{8}{|l|}{$\mathrm{T}_{3}(\mathrm{nmol} / \mathrm{L})$} \\
\hline 2 weeks & $0.73 \pm 0.25$ & $1.08 \pm 0.32$ & $1.24 \pm 0.32$ & $2.21 \pm 0.54$ & $<0.001$ & 1.000 & $\mathrm{~A}<\mathrm{B}, \mathrm{C}, \mathrm{D} ; \mathrm{B}, \mathrm{C}<\mathrm{D}$ \\
\hline 4 weeks & $1.34 \pm 0.46$ & $1.60 \pm 0.33$ & $1.64 \pm 0.23$ & $2.59 \pm 0.40$ & $<0.001$ & 1.000 & $\mathrm{~A}, \mathrm{~B}, \mathrm{C}<\mathrm{D}$ \\
\hline 40 weeks PCA & $2.77 \pm 1.11$ & $2.49 \pm 1.41$ & $2.01 \pm 0.13$ & $2.59 \pm 0.40$ & ns & 0.433 & - \\
\hline
\end{tabular}

Data are presented as mean $\pm \mathrm{SD}$.

$\mathrm{TSH}$, thyrotropin; $\mathrm{FT}_{4}$, free thyroxine; $\mathrm{T}_{3}$, triiodothyronine; $\mathrm{PCA}$, postconceptional age. 
Table 3. Three-Month Neurocognitive Assessment Results According to Gestational Age Group

\begin{tabular}{|c|c|c|c|c|c|c|c|c|}
\hline $\begin{array}{l}\text { Neurocognitive } \\
\text { measure }\end{array}$ & $\begin{array}{c}\text { A: } \\
24-26 \text { weeks } \\
(\mathrm{n}=10)\end{array}$ & $\begin{array}{c}B: \\
27-29 \text { weeks } \\
(\mathrm{n}=23)\end{array}$ & $\begin{array}{c}\text { C: } \\
\text { 30-32 weeks } \\
(\mathrm{n}=20)\end{array}$ & $\begin{array}{c}D: \\
33-35 \text { weeks } \\
(n=11)\end{array}$ & $\begin{array}{c}E: \\
37-42 \text { weeks } \\
(\mathrm{n}=33)\end{array}$ & $\underset{\text { value }}{\mathrm{p}}$ & $\begin{array}{l}\text { Observed } \\
\text { power }\end{array}$ & $\begin{array}{c}\text { Post hoc } \\
\text { comparisons }^{\mathrm{b}}\end{array}$ \\
\hline MDI & $100.80 \pm 5.77$ & $100.65 \pm 10.68$ & $105.05 \pm 7.69$ & $102.36 \pm 10.20$ & $107.76 \pm 6.69$ & 0.018 & 0.799 & $\mathrm{~B}<\mathrm{E}$ \\
\hline PDI & $98.40 \pm 3.44$ & $98.26 \pm 5.11$ & $101.90 \pm 4.75$ & $98.82 \pm 6.72$ & $101.15 \pm 4.19$ & 0.052 & 0.680 & - \\
\hline $\begin{array}{l}\text { Selective } \\
\text { attention }\end{array}$ & $3.50 \pm 0.82$ & $4.32 \pm 0.55$ & $4.18 \pm 0.87$ & $3.90 \pm 1.14$ & $4.52 \pm 0.67$ & 0.005 & 0.895 & $\mathrm{~A}<\mathrm{B}, \mathrm{E}$ \\
\hline $\begin{array}{l}\text { Sustained } \\
\text { attention }\end{array}$ & $2.50 \pm 0.67$ & $2.91 \pm 0.29$ & $2.94 \pm 0.22$ & $2.70 \pm 0.46$ & $2.94 \pm 0.24$ & 0.003 & 0.913 & $\mathrm{~A}<\mathrm{B}, \mathrm{C}, \mathrm{E}$ \\
\hline Attention shift & $1.63 \pm 0.66$ & $1.73 \pm 0.44$ & $1.88 \pm 0.30$ & $1.70 \pm 0.46$ & $1.64 \pm 0.49$ & ns & 0.301 & - \\
\hline Total attention & $7.62 \pm 1.88$ & $8.95 \pm 1.17$ & $8.97 \pm 1.17$ & $8.30 \pm 1.73$ & $9.09 \pm 0.80$ & 0.007 & 0.878 & $\mathrm{~A}<\mathrm{B}, \mathrm{C}, \mathrm{E}$ \\
\hline $\begin{array}{l}\text { BRI attention } \\
\text { scale }\end{array}$ & $38.80 \pm 4.08$ & $39.22 \pm 3.25$ & $39.60 \pm 2.96$ & $38.18 \pm 4.56$ & $37.94 \pm 3.45$ & ns & 0.276 & - \\
\hline $\begin{array}{l}\text { BRI motor } \\
\text { scale }\end{array}$ & $34.00 \pm 1.05$ & $33.96 \pm 0.88$ & $34.20 \pm 0.70$ & $34.36 \pm 0.67$ & $33.91 \pm 0.95$ & ns & 0.246 & - \\
\hline
\end{tabular}

Data are presented as mean $\pm \mathrm{SD}, F(4,93)$.

${ }_{1} p$ values reflect MANOVA results for each neurocognitive measure.

${ }^{\mathrm{b}}$ Post hoc comparisons used Tukey's HSD.

MDI, mental development index; PDI, psychomotor development index; BRI, behavior rating index.

nificantly explained by high 2-week $\mathrm{FT}_{4}$ and bilirubin levels, use of prenatal corticosteroids, and absence of sepsis, which accounted for $38.6 \%$ of its variance.

\section{Discussion}

The present study sought to investigate whether preterm infants would show deficits in neurodevelopment and attention at 3 months of age and whether these measures were affected by TH levels and neonatal medical morbidities.

Visual attention problems are common in children born preterm (14). For the first time, we have shown that preterm birth is associated with attention deficits at 3 months of life; in addition to delays in overall mental development, various aspects of attention were delayed, including total, selective, and sustained attention. Our results are consistent with those of Elgen and colleagues (21) who found that preterm children were significantly more inattentive than full-term controls, had greater difficulty with selective attention, and slower reaction times on tests of alternating attention. Our previous study investigating attention in preterm infants used the same BSID-II attention measures we applied presently and found no differences between infants born 30-35 weeks gestation and full-term controls (9).

Importantly, our present attention findings were driven by the most extremely preterm group, those infants born before 27 weeks gestation. In line with these findings, previous studies have shown that infants born $<30$ weeks gestation are at a higher risk of neurocognitive impairment $(10,13,14)$. However, we now found that it was not gestational age alone, but gestational age plus low $\mathrm{TH}$ and presence of certain medical morbidities that contributed to lower attention and neurodevelopmental scores. Specifically, low 2-week $\mathrm{FT}_{4}$ levels were associated with deficits in selective, sustained, and total attention and contributed to a significant proportion of variance in these measures. In line with these findings, research has shown that lower neonatal TH levels in ex-preterm children were associated with a number of neurocognitive deficits, including reduced mental and motor development scores at 2 and 5 years, and difficulties in school performance

Table 4. Summary of Regression Analyses for Predictors of 3-month Neurocognitive Ability

\begin{tabular}{|c|c|c|c|c|}
\hline Neurodevelopmental measure & Preterm factors & $\beta$ & $S E$ & $\mathrm{p}$ value \\
\hline \multirow[t]{2}{*}{$\operatorname{MDI}\left(R^{2}=13.5 \%, p=0.013\right)$} & PDA & -5.946 & 2.392 & 0.016 \\
\hline & Sepsis & -5.329 & 3.492 & ns \\
\hline \multirow[t]{3}{*}{ Selective attention $\left(R^{2}=19.2 \%, p=0.007\right)$} & $\mathrm{FT}_{4}(2$ weeks $)$ & 0.022 & 0.024 & ns \\
\hline & $\mathrm{T}_{3}(40$ weeks PCA) & -0.320 & 0.185 & 0.090 \\
\hline & Bilirubin & 0.006 & 0.003 & 0.043 \\
\hline \multirow{5}{*}{ Sustained attention $\left(R^{2}=44.2 \%, p<0.001\right)$} & $\mathrm{FT}_{4}(2$ weeks $)$ & 0.020 & 0.010 & 0.053 \\
\hline & Prenatal corticosteroids & 0.393 & 0.114 & 0.001 \\
\hline & Bilirubin & 0.002 & 0.001 & ns \\
\hline & Sepsis & -0.503 & 0.144 & 0.001 \\
\hline & PDA & -0.165 & 0.100 & ns \\
\hline \multirow[t]{4}{*}{ Total attention $\left(R^{2}=38.6 \%, p<0.001\right)$} & $\mathrm{FT}_{4}(2$ weeks $)$ & 0.098 & 0.034 & 0.005 \\
\hline & Prenatal corticosteroids & 1.188 & 0.392 & 0.004 \\
\hline & Bilirubin & 0.007 & 0.004 & ns \\
\hline & Sepsis & -1.393 & 0.493 & 0.007 \\
\hline
\end{tabular}

PDA, patent ductus arteriosus; sepsis, confirmed infection. 
at 9 years of age $(8,10,22,23)$. The present study therefore adds attention deficits in infants to the documented cognitive domains potentially affected by hypothyroxinemia of prematurity.

In the present study, a number of neonatal morbidities, including the presence of PDA and sepsis, as well as elevated bilirubin and use of prenatal corticosteroids, were associated with deficient TH levels and worse performance on MDI and selective, sustained, and total attention. The presence of PDA was associated with lower 2-week $\mathrm{FT}_{4}$ levels and worse performance on MDI and sustained attention. Sepsis was associated with lower 40-week PCA $\mathrm{T}_{3}$ levels and worse performance on MDI and sustained and total attention. Similar to our findings, Williams and colleagues (16) demonstrated an association between reduced TH levels and the presence of PDA and infection in preterm infants. We also found that elevated bilirubin levels correlated with elevated 2 week $\mathrm{FT}_{4}$ levels and decreased 40 week-PCA $\mathrm{T}_{3}$ levels and with better visual attention. In line with our findings, Lim and colleagues (24) have suggested that elevated bilirubin may be at least partly responsible for $\mathrm{T}_{4}$ transport inhibition in $\mathrm{T}_{3-}$ producing tissues, such as the liver, and thus lead to low plasma $\mathrm{T}_{3}$ levels. Whereas our findings implicated PDA, sepsis, and bilirubin as neurocognitive modulators, past research has linked other nonthyroidal illnesses, such as bronchopulmonary dysplasia, brain injury, and severe retinopathy to poorer long-term outcome (25). Thus, it may be that while corticosteroids, PDA, sepsis, and bilirubin affect cognitive outcome at 3 months, other factors may prove significant later in development.

The strengths of our study include combining measurements of $\mathrm{TH}$ levels at three time points with a detailed neurodevelopmental assessment. However, there are several limitations of the present study. Notably, the overall sample size was relatively small, involving only 65 preterm infants and 33 controls; the groups were unequal in size, sex, and SES distributions. Although our goal was to assess 35 infants in each of our five gestational age groups, we found it difficult to recruit the oldest preterm infants because parents were hesitant to label their children as anything other than healthy and normal for their slight prematurity except thus they were unwilling to allow newborns to undergo blood testing. The youngest preterm group, which was the sickest and most prone to complications, either had a high mortality rate or parents were too stressed to agree to participation by 2 weeks of age. Secondly, we were unable to obtain initial TSH levels from the newborn screening lab due to legal restrictions and Group D only had two blood tests, whereas the other groups all had three. Thirdly, we analyzed the blood samples for only three THs and did not include total $\mathrm{T}_{4}$. But given that the developing brain depends on circulating $\mathrm{FT}_{4}$ for local intracellular $\mathrm{T}_{3}$ generation (26), it is thus most important to address $\mathrm{FT}_{4}$ levels when considering the effects of $\mathrm{TH}$ on brain development.

\section{Conclusions}

Reduced levels of $\mathrm{TH}$ in the neonatal period in preterm infants are associated with a reduced neurocognitive outcome in the attention domain at 3 months corrected age. These findings encourage further study of the role of $\mathrm{TH}$ on brain development in preterm infants.

\section{Acknowledgments}

We would like to thank Kelly Nash and Meagan Williamson for carrying out the Bayley assessments, and Jennifer Vaughan for collecting blood samples from discharged infants. We would also like to thank March of Dimes for funding this project.

\section{Disclosure Statement}

No competing financial interests exist.

\section{References}

1. Bernal JN, Nunez J 1995 Thyroid hormones and brain development. Eur J Endocrinol 133:390-398.

2. van Wassenaer AG, Kok JH 2000 Thyroid function and thyroid hormone requirements of very preterm infants. NeoReviews 1:e116-121.

3. Kilby MD, Gittoes N, McCabe C, Verhaeg J, Franklyn JA 2000 Expression of thyroid receptor isoforms in the human fetal central nervous system and the effects of intrauterine growth restriction. Clin Endocrinol 53:469-477.

4. Contempre B, Jauniaux E, Calvo R, Jurkovic D, Campbell S, de Escobar GM 1993 Detection of thyroid hormones in human embryonic cavities during the first trimester of pregnancy. J Clin Endocrinol Metab 77:1719-1722.

5. Calvo RM, Jauniaux E, Gulbis B, Asunción M, Gervy C, Contempré B, Morreale de Escobar G 2002 Fetal tissues are exposed to biologically relevant free thyroxine concentrations during early phases of development. J Clin Endocrinol Metab 87:1768-1777.

6. Uhrmann S, Marks KH, Maisels MJ, Friedman Z, Murray F, Kulin HE, Kaplan M, Utiger R 1998 Thyroid function in the preterm infant: a longitudinal assessment. J Pediatr 92:968973.

7. Williams FL, Simpson J, Delahunty C, Ogston SA, BongersSchokking JJ, Murphy N, van Toor H, Wu SY, Visser TJ, Hume R; Collaboration from the Scottish Preterm Thyroid Group 2004 Developmental trends in cord and postpartum serum thyroid hormones in preterm infants. J Clin Endocrinol Metab 89:5314-5320.

8. Reuss ML, Paneth N, Pinto-Martin JA, Lorenz JM, Susser MB 1996 The relation of transient hypothyroxinemia in preterm infants to neurologic development at two years of age. N Engl J Med 334:821-827.

9. Ishaik G, Asztalos E, Perlman K, Newton S, Frisk V, Rovet J 2000 Hypothyroxinemia of prematurity and infant neurodevelopment: a pilot study. J Dev Behav Pediatr 21:172179.

10. van Wassenaer AG, Briët JM, van Baar A, Smit BJ, Tamminga P, de Vijlder JJ, Kok JH 2002 Free thyroxine levels during the first weeks of life and neurodevelopmental outcome until the age of 5 years in very preterm infants. Pediatrics 109:534-539.

11. Hack M, Taylor HG, Klein N, Eiben R, Schatschneider C, Mecuri-Minich N 1994 School-age outcome of a regional cohort of $<750 \mathrm{gm}$ birthweight children. N Engl J Med 331: 753-759.

12. Taylor HG, Klein N, Schatschneider C, Hack M 1998 Predictors of early school age outcomes in very low birth weight children. J Dev Behav Pediatr 19:1-9.

13. Vohr BR, Wright LL, Dusick AM, Mele L, Verter J, Steichen JJ, Simon NP, Wilson DC, Broyles S, Bauer CR, DelaneyBlack V, Yolton KA, Fleisher BE, Papile LA, Kaplan MD 2000 
Neurodevelopmental and functional outcomes of extremely low birth weight infants in the National Institute of Child Health and Human Development Neonatal Research Network, 1993-1994. Pediatrics 105:1216-1226.

14. Anderson PJ, Doyle LW 2008 Cognitive and educational deficits in children born extremely preterm. Semin Perinatol 32:51-58.

15. Mirabella G, Feig D, Astzalos E, Perlman K, Rovet J 2000 The effect of abnormal intrauterine thyroid hormone economies on infant cognitive abilities. J Ped Endocrinol Metab 13:191194.

16. Williams FLR, Ogston SA, van Toor H, Visser TJ, Hume R 2005 Serum thyroid hormones in preterm infants; associations with postnatal illnesses and drug usage. J Clin Endocrinol Metab 90:5954-5963.

17. Hollingshead AB, Redlich FC 1958 Social Class and Mental Illness: A Community Study. New York, John Wiley \& Sons.

18. The committee for the classification of Retinopathy of prematurity (No authors listed) 1984 An international classification of retinopathy of prematurity. Pediatr 74:127-133.

19. Bayley N 1993 Bayley Scales of Infant Development, 2nd edition. The Psychological Corporation, San Antonio, TX.

20. Donders ART, van der Heijden GJMG, Stijnen T, Moons KGM 2006 Review: a gentle introduction to imputation of missing values. J Clin Epidemiol 59:1087-1091.

21. Elgen I, Lundervold AJ, Sommerfelt K 2004 Aspects of inattention in low birth weight children. Pediatr Neurol 30:92-98.

22. Meijer WJ, Verloove-Vanhorick SP, Brand R, van den Brande JL 1992 Transient hypothyroxinaemia associated with developmental delay in very preterm infants. Arch Dis Child 67:944-947.
23. den Ouden AL, Kok JH, Verkerk PH, Brand R, VerlooveVanhorick SP 1996 The relation between neonatal thyroxine levels and neurodevelopmental outcome at age 5 and 9 years in a national cohort of very preterm and/or very low birth weight infants. Pediatr Res 39:142-145.

24. Lim CF, Docter R, Visser TJ, Krenning EP, Bernard B, van Toor H, de Jong M, Hennemann G 1993 Inhibition of thyroxine transport into cultured rat hepatocytes by serum of nonuremic critically ill patients: effects of bilirubin and nonesterified fatty acids. J Clin Endocrinol Metab 76:11651172.

25. Schmidt B, Asztalos EV, Roberts RS, Robertson CMT, Sauve RS, Whitfield MF 2003 Impact of bronchopulmonary dysplasia, brain injury, and severe retinopathy on the outcome of extremely low-birth-weight infants at 18 months. Results from the trail of indomethacin prophylaxis in preterms. JAMA 289:1124-1129.

26. Morreale de Escobar G, Obregon MJ, Escobar del Rey F 2000 Is neuropsychological development related to maternal hypothyroidism or to maternal hypothyroxinemia? J Clin Endocrinol Metab 85:3975-3987.

Address reprint requests to: Joanne Rovet, Ph.D.

Department of Psychology

The Hospital for Sick Children 555 University Ave.

Toronto, ON M5G 1X8

Canada

E-mail: joanne.rovet@sickkids.ca 


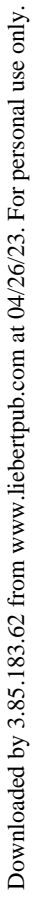

